\title{
WEB PORTAL USABILITY AMONG NIGERIAN UNIVERSITY STUDENTS: A CASE STUDY OF UNIVERSITY OF BENIN, NIGERIA
}

\author{
F. 0. Oliha \\ DEPARTMENT OF COMPUTER SCIENCE, UNIVERSITY OF BENIN, NIGERIA \\ E-mail address: oliha_festus@uniben.edu
}

\begin{abstract}
The web portal technology by Nigerian universities was adopted as a way to help curb one of the burdens of university's principal managerial operations: "students' academic management". This study evaluates usability or "ease of use" of University of Benin (UNIBEN) web portal from the students' holistic view through the four usability constructs (interface and information quality, system usefulness and overall satisfaction) of the developed Web Portal Usability Success (WEBPUS) Model. It revealed that the informative features and usefulness of the web portal system has not encouraged students' usability behaviour due to the portal's inefficiencies to effectively and satisfactorily achieve a range of specified or completed tasks irrespective of their competences in basic computer and internet capabilities.
\end{abstract}

Keywords: Internet, web portal usability, portal usefulness, efficiency, effectiveness, webometrics and ICT competence.

\section{INTRODUCTION}

The internet technology has globally become a paramount necessity to the educational the continent as the traditional approach of managing student's record is no longer an option in the $21^{\text {st }}$ century. This cognizance alone has increased the number of prospective students seeking admission into higher institutions, creating an uncomfortable platform for universities to manage and process student records and information on a yearly basis given the rate of their demands to acquire knowledge. The internet in most organizations gives communication access to users and enhances interaction with the public .The technological impact of the internet in education enhance access information and operational processes for efficient management of students' academic, institutional tasks and administrative activities via the portal technology. A web portal by definition is a gateway, a front door to other portals or sites [1]. In this study, it is referred to, as a web technology that provides a starting point or gateway to other resources on the Internet or an intranet with certain features including: a single point of entry to applications and services, the ability to communicate and collaborate, personalization, and integration of functions and data from multiple systems. It is a platform for organizations - universities, colleges, companies to leverage managerial resources and data for efficient communication and other in-house operations [2]. University websites give information regarding the university but does not process student records and study progress. With the ever increasing population of new intakes, the manual method of processing new and old students has necessitated the need for the processing and management of student's records via the internet. To this end, tertiary institutions are now employing web portal technologies, applications and systems as a subset of the internet to curb some managerial and academic related burdens thereby creating access to a volume of stakeholder's information from a single point of view. A recent study on university web portals as noted in [1] exposed that user's perception of University Web Portal usability of tertiary institutions (University of Benin, Benin City) in Nigeria is less satisfactory stating that Universities with web portals must have to consider certain functions and features when planning a portal system, such as how to develop tools to store and properly retrieve information, why and what users will use the portal for or how these technologies

* Corresponding author, Tel: +234-8028821612 
will affect the perception and behaviour of the users (students in this case). This study seeks to look at usability capability and effectiveness of University of Benin (UNIBEN) web portals by students of Nigerian universities using UNIBEN as a case study with a view of how efficient they are in presenting information required by and for the students (users) or if they are used as they should.

\section{BACKGROUND AND LITERATURE REVIEW}

The popularity, intensity of use, and penetration of the Web and Portal technology has not only changed the online process of processing students' record, but it has also modified both the access to student information available and how students engage and collaborate with each other on the portal [3]. Many universities have started initiatives on using the web Portal technology as an information management tool to deliver education to students [4]. Despite the restricted IT budgets, investments in portal solutions for tertiary institutions are still growing in this part of the continent [1]. University of Benin amongst many is still investing huge amounts of money in building and currently through the International ICT Centre maintaining her portal system (kofa) known as the West African e-University Project (WAeUP), which is a powerful and comprehensive Student Management System providing a single access point to educational resources and information to all University of Benin students.

WAeUP is a Nigerian-German cooperation initially founded in 2005 by Broadband Technologies (Lagos, Nigeria), Netplux (Accra, Ghana), Scientific African (Luechow, Germany) and freelance programmers from Germany with a focus on the development of Open Source web solutions to administrate universities, colleges or schools online at a reasonable price. Since it started in 2005, the core business of WAeUP has been the development of a scalable and customizable Internet platform to facilitate the acquisition and management of student data, to control the workflow of student registration processes, and to ensure regular payment of school fees with the help of modern payment technologies such as webpay etc. The Student Registration Portal (SRP) has been developed in cooperation with the University of Benin in Nigeria and first launched in 2006. Meanwhile the portal is successfully running at eight academic institutions in Nigeria (University of Benin, Federal University of Technology, Federal College of Education, Adekunle Ajasin University,
Ambrose Alli University, Kwara State Polytechnic amongst others). In 2008, the second-generation portal which was developed from the scratch while using the experience gained with the SRP, which paved way for a new system called Kofa: a part of WAeUP which currently is used for processing student's activities online and has helped UNIBEN emerge twice as the best in webometrics. It is equipped with the same functionality as SRP but also with an additional focus on reports which documents the students' behaviour and study progress.

In webometrics, UNIBEN dropped to the $8^{\text {th }}$ position at the first quarter of 2013 [5]. This cognizance motivated the scope of this study to look at the usability or "ease of use" of UNIBEN web portal (kofa) from the view of students' who are users of this technology and thus, it is important to know what usability means to students, as numerous research studies as noted in [3], have documented that users become disoriented and "lost in hyperspace, hence unable to find the information they need. Awareness of this potential problem raises the question of whether the effectiveness of web portal is affected by the extent to which they meet usability standards.

Usability of the web portal plays a central role in establishing a healthy communication between the university and its stakeholders. Thus, the intention by the students to use it on a continual basis (which is usability) is highly dependent on its ability to attract, help and efficiently process with ease of use, an organized, meaningful and useful data thereby fulfilling a specified range or given tasks to them. Usability can be described in different perspectives as Shackel in [6] described usability as "a technology's capability to be used easily and effectively by the specified range of users, given specified training and user support, to fulfill the specified range of tasks, within the specified range of environmental scenarios". With the view of less effort, [7] expressed usability as the ease of use and ease of learning that implied providing users with systems requiring minimum cognitive and physical effort to accomplish users' needs and expectations. [8] on the other hand expressed that usability is a measure in which a system can be learned and used, its safety, effectiveness and efficiency and the attitude of its users towards it. As noted in [6], there are numerous tools for evaluating website/portal usability. Some examples are, QUIS (Questionnaire for User Interface Satisfaction), SUMI (Software Usability Measurement Inventory), NIST Web Metrics (The National Institute 
of Standards and Technology Web Metrics) and WAMMI (website analysis and measurement inventory questionnaire) to assess web sites/portals [9], Bobby: Bobby is a Web accessibility software tool designed to help expose and repair barriers to accessibility and encourage compliance with existing accessibility guidelines, Protocol Analysis: The protocol analysis or "think aloud" is based on direct observation of a real interaction between the user and the system [10], the ASQ (The After-Scenario Questionnaire) the CSUQ (The Computer System Usability Questionnaire) and the PSSUQ (The Post Study System Usability Questionnaire) is intended primarily for assessment of user satisfaction with the usability of a system [11].

The PSSUQ/CSUQ was developed in 1993 for IBM, containing 19 questions and provides opportunity for open-ended user comments [11]. Items selected from these questionnaires assess four areas of usability which were used to develop Web Portal Usability Success (WEBPUS) model, while adding an additional criteria known as ICT Competence Level as seen in Figure 1. This model is used to measure usability behaviour of a given web portal to examine and determine its success, with the notion of exposing the impact of using such a portal system to its stakeholders. Describing web portals as a type of information systems, it is proper to define their success with regards to usability measuring model with interdependencies between the different success variables. The model can be interpreted as follows:

- ICT Competence is a construct that measures the user's capability to use a system, internet or the web. It is required as a basic necessity or tool for determining the users to examine the WEBPUS Model. It is made up of eight (8) items.

- System Usefulness (System Use) is the construct that inquires about the effectiveness and efficiency of the system usefulness in performing and completing a specified task. It is made up of eight (8) items.

- Interface Quality construct targets the general quality and functionality of the system interface. It consists of three (3) items.

- Information Quality construct addresses the ability of the system in support of information and error handling consisting of six (6) items.
- Overall (Web Portal) Usefulness Satisfaction is a construct that expresses the satisfaction of using the system with just two (2) items on it.

Describing the model as a whole, the construct of user's ICT competence level on the WEBPUS model served as an input tool to evaluate and examine the UNIBEN web portal through the four usability constructs (interface and information quality, system usefulness and overall satisfaction) producing an output for decision making enhancement. The WEBPUS model is used as a post study evaluation tool on a recent research by [1] to evaluate UNIBEN web portal with respect to capability (the ability to use a system), usability (attitude to use and ease of use) and efficiency (system's resources in achieving a task).

\section{RESEARCH DESIGN}

This study seeks to explore what the construct of usability means for students being managed by UNIBEN web portal thereby referring usability or ease of use as a construct of behaviour or attitude resulting from their experiences and expectations of the portal and what satisfaction means to and for them from their interactions with the web portal system. It in essence, seeks with a view to help understand usability and provide a guideline or framework for improving web portal development for Nigerian universities (owners and others yet to adopt such technology). The target population of the study comprises the full time and part time (Diploma and Degree) undergraduates and postgraduates students of the University of Benin (UNIBEN), Benin City, Edo State, Nigeria.

\subsection{Research Approach and Methodology}

A survey approach was employed using constructs from WEBPUS model developed from the PSSUQ and CSUQ questionnaires. The use of questionnaire was employed as the survey instrument which was made up of five different sections and consisted of a total of 27 items with evaluation keys ranging from Strongly Agree to Strongly Disagree and Highly Satisfactory to Highly Dissatisfactory which were used to gather data that elicited information from the participants (students) regarding their ICT/internet competences, system quality and usefulness of the portal by simply ticking from the range of options that best suit their responses. 


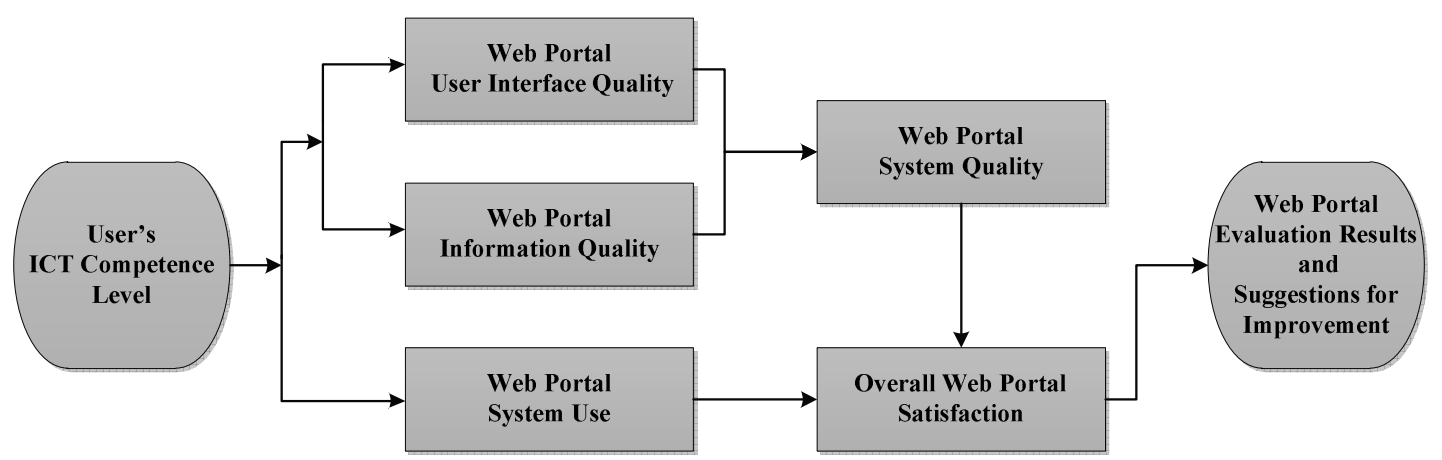

Figure 1: Web Portal Usability Success (WEBPUS) Model (Author's image)

Questionnaires were administered to participants at UNIBEN Central Record Processing Unit (CRPU) which is in charge of all students' online academic activities. A total of 400 samples of the questionnaires were filled and returned immediately as participants were guided upon administration, giving a response rate of $100 \%$. The data gathered were analyzed with a simple percentage count for simplicity of presentation and understandability.

\subsection{Data Presentation and Result Analysis}

Table 1 presents information on ICT competence level with the aim to assess participant's ICT capability on the usage of computer and internet related activities, revealing that 387 participants about $96.8 \%$ can averagely use the computer system as $328(82 \%)$ of them can use it for offline tasks while 394 (98.5\%) were able to use the system for internet and web related activities, with about 177(44.9\%) and $168(42.6 \%)$ accessing the internet most preferably by smart phones and laptop PCs while 313 which is about 79.4\% preferred cyber café as their method of accessing and performing tasks on the university web portal. This is an indication that the participants were ICT and internet competent but activities regarding the usability of the university web portal system were mostly carried out via cyber cafes probably due to the nature of the system.

On the query of time usage with respects to the data gathered on computer competency and internet ability, Table 2 reveals that majority of the participants about $70 \%(32.8+37.2)$ acquaint themselves up to about 1 to10 hours with the computer on a weekly basis as about $96.4 \%(41.1+$ 55.3) has durably been using the internet or web for about 1 to 10 years of which majority 58.6\% spends about 11 to 20 hours surfing on a weekly basis but almost the total participants about $99.2 \%$ spend less than 1 hour using the web portal on a weekly basis.

Table 1: Respondent's ICT Competence Profile

\begin{tabular}{|c|c|c|c|}
\hline Preferences & \multicolumn{3}{|c|}{ Participant's Responses } \\
\hline \multirow{2}{*}{ ICT Competence Assessment } & \multicolumn{3}{|c|}{ Frequency $(\%)$} \\
\hline & Yes & No & Total \\
\hline Can you averagely use the computer system? & $387(96.8 \%)$ & $13(03.2 \%)$ & $400(100 \%)$ \\
\hline $\begin{array}{l}\text { Do you use the computer system for performing any task such as: desktop } \\
\text { publishing, application, appreciation and others? }\end{array}$ & $328(82.0 \%)$ & $72(18.0 \%)$ & $400(100 \%)$ \\
\hline Do you use the internet/web? & $394(98.5 \%)$ & $06(01.5 \%)$ & $400(100 \%)$ \\
\hline \multirow[b]{2}{*}{ Most preferable method of accessing the internet or web portal: } & \multicolumn{3}{|c|}{ Frequency (\%) } \\
\hline & \multicolumn{2}{|c|}{ Internet $\quad U$} & $\begin{array}{l}\text { UNIBEN Web } \\
\text { Portal }\end{array}$ \\
\hline Desktop PCs & \multicolumn{2}{|c|}{$26(06.6 \%)$} & $06(01.5 \%)$ \\
\hline Laptop PCs & \multicolumn{2}{|c|}{$168(42.6 \%)$} & $32(08.1 \%)$ \\
\hline iPads/Tablets PCs & \multicolumn{2}{|c|}{$03(0.80 \%)$} & $13(03.3 \%)$ \\
\hline Smartphones & \multicolumn{2}{|c|}{$177(44.9 \%)$} & $30(07.6 \%)$ \\
\hline Cyber Cafes & \multicolumn{2}{|c|}{$20(05.1 \%)$} & $313(79.4 \%)$ \\
\hline Total & \multicolumn{2}{|c|}{$394(100 \%)$} & $394(100 \%)$ \\
\hline
\end{tabular}


Table 2: Respondents ICT Profile on Time Usage

\begin{tabular}{|c|c|c|c|c|c|}
\hline \multirow{2}{*}{$\begin{array}{l}\text { Preferences } \\
\text { Time Usage }\end{array}$} & \multicolumn{5}{|c|}{ Participant's Evaluation on Time Usage } \\
\hline & \multicolumn{4}{|c|}{ Frequency $(\%)$} & Total \\
\hline \multirow{2}{*}{$\begin{array}{l}\text { How many hours do you use the computer } \\
\text { system per week? }\end{array}$} & $1-5$ hours & $6-10$ hours & 11 -20hours & $\begin{array}{c}21 \text { - 40hours } \\
+\end{array}$ & \multirow[t]{2}{*}{$387(100 \%)$} \\
\hline & $127(32.8 \%)$ & $144(37.2 \%)$ & $78(20.2 \%)$ & $38(09.8 \%)$ & \\
\hline \multirow{2}{*}{$\begin{array}{l}\text { How long have you been using the internet } \\
\text { or web? }\end{array}$} & 1 - 5years & $6-10$ years & 11 -15years & $16-20$ years + & \multirow[t]{2}{*}{$394(100 \%)$} \\
\hline & $162(41.1 \%)$ & $218(55.3 \%)$ & $12(03.0 \%)$ & $02(0.50 \%)$ & \\
\hline \multirow{2}{*}{$\begin{array}{l}\text { How many hours do you use the } \\
\text { internet/web per week? }\end{array}$} & 1 - 5hours & $6-10$ hours & 11 -20hours & 21 - 40hours + & \multirow[t]{2}{*}{$394(100 \%)$} \\
\hline & $59(15.0 \%)$ & $98(24.9 \%)$ & $231(58.6 \%)$ & $06(01.5 \%)$ & \\
\hline \multirow{2}{*}{$\begin{array}{l}\text { How many hours do you spend using the } \\
\text { UNIBEN web portal per week? }\end{array}$} & $<1$ hour & $1-3$ hours & 4 -6hours & 7 - 15 hours + & \multirow[t]{2}{*}{$394(100 \%)$} \\
\hline & $391(99.2 \%)$ & $03(0.80 \%)$ & $00(0.00 \%)$ & $00(0.00 \%)$ & \\
\hline
\end{tabular}

Table 3: Web Portal System Quality Profile.

\begin{tabular}{|c|c|c|c|c|c|}
\hline \multirow[b]{3}{*}{ Web Portal Information Quality } & \multicolumn{5}{|c|}{ Participant's Evaluation on Web Portal Information Quality } \\
\hline & \multicolumn{5}{|c|}{ Frequency (\%) } \\
\hline & $\begin{array}{l}\text { Strongly } \\
\text { Agree }\end{array}$ & Agree & Neutral & Disagree & $\begin{array}{l}\text { Strongly } \\
\text { Disagree }\end{array}$ \\
\hline $\begin{array}{l}\text { The system gave error messages that } \\
\text { clearly told me how to fix problems. }\end{array}$ & $10(02.5 \%)$ & $29(07.4 \%)$ & $56(14.2 \%)$ & $30(07.6 \%)$ & $269(68.3 \%)$ \\
\hline $\begin{array}{l}\text { The information provided (such as on- } \\
\text { line help, on-screen messages and other } \\
\text { documentation) on how to use the system } \\
\text { was clear. }\end{array}$ & $42(10.7 \%)$ & $72(18.3 \%)$ & $261(66.2 \%)$ & $11(02.8 \%)$ & $08(02.0 \%)$ \\
\hline $\begin{array}{l}\text { It was easy to find the information I } \\
\text { needed. }\end{array}$ & $22(05.6 \%)$ & $78(19.8 \%)$ & $77(19.5 \%)$ & $176(44.7 \%)$ & $41(10.4 \%)$ \\
\hline $\begin{array}{l}\text { The information provided for the system } \\
\text { was easy to understand. }\end{array}$ & $42(10.7 \%)$ & $58(14.7 \%)$ & $212(53.8 \%)$ & $54(13.7 \%)$ & $28(07.1 \%)$ \\
\hline $\begin{array}{l}\text { The information was effective in helping } \\
\text { me complete the tasks and scenarios. }\end{array}$ & $13(03.3 \%)$ & $60(15.2 \%)$ & $179(45.4 \%)$ & $116(29.4 \%)$ & $26(06.6 \%)$ \\
\hline $\begin{array}{l}\text { The organization of information on the } \\
\text { system screens was clear. }\end{array}$ & $47(11.9 \%)$ & $196(49.7 \%)$ & $48(12.2 \%)$ & $83(21.1 \%)$ & $20(05.1 \%)$ \\
\hline Web Portal Interface Quality & \multicolumn{5}{|c|}{ Participant's Evaluation on Web Portal Interface Quality } \\
\hline $\begin{array}{l}\text { The interface of the portal system was } \\
\text { pleasant and well organized. }\end{array}$ & $116(29.4 \%)$ & $216(54.8 \%)$ & $20(05.1 \%)$ & $34(08.6 \%)$ & $08(02.0 \%)$ \\
\hline $\begin{array}{l}\text { I liked using the interface of the web } \\
\text { portal system. }\end{array}$ & $21(05.3 \%)$ & $99(25.1 \%)$ & $12(03.0 \%)$ & $221(56.1 \%)$ & $41(10.4 \%)$ \\
\hline $\begin{array}{l}\text { The web portal system has all the } \\
\text { functions and capabilities I expect it to } \\
\text { have. }\end{array}$ & $15(03.8 \%)$ & $55(14.0 \%)$ & $20(05.1 \%)$ & $106(26.9 \%)$ & $198(50.3 \%)$ \\
\hline
\end{tabular}

This is an indication that although majority of the participants engage themselves with the system and surf the internet on a weekly basis wherein the UNIBEN web portal is a subset, the amount of time spent on the portal shows that it is less used by the participants.

Information presented on Table 3 evaluated participants on the quality of the University Web Portal System with two key constructs that made up the system quality of the WEBPUS model: Portal Information Quality and Portal Interface Quality. Responding to the query of finding the right information needed, participants about $44.7 \%$ on this query did not agree as over half of them $53.8 \%$ were uncertain that the information provided by the system was easy to understand because majority of them $66.2 \%$ could not tell whether or not the information was clear to them as they $45.4 \%$ were also indifferent with regards to completing their tasks due to ineffectiveness of the information provided by the system. Almost half of the participants $49.7 \%$ agreed that information organization on the system screen was clear. There is an indication here that although the information and the interface of the portal system were well organized on the screen, participants prefer not to use the system themselves and could not 
ascertain to the fact that it was helpful in completing their tasks or aided their learning experiences majorly because if an error was made, it was difficult to recover as many $68.3 \%$ highly disagreed on the error messages intended to fix the mistake made. In other words solely, the portal system lacks some of the expected information, capabilities, functions and features they expected.

In order to achieve the best efficiency and effectiveness of a system, users must first learn how to use or interact with the system [7].Table 4 evaluated participants on the construct of web portal usability or usefulness with respect to learnability (ease to use). On the query of simplicity using the portal, participants about $56.1 \%$ were pleased but certain $45.4 \%$ were not so sure that it was easy to learn using the portal system after carrying out an online task since they were unable to tell if their learning experiences have improved while using the web portal system. Responding to the items on effectiveness and efficiency, it is obvious from the findings that majority of the participants were not pleased regarding the usefulness of the web portal system for performing and completing their tasks with the indication that they experience difficulty and felt uncomfortable to recover from errors or mistakes. This is to say that, on the construct of usefulness with respect to learnability and ease to use, the participants cannot efficiently complete their task while using the portal system.

Table 5 presents data on the WEBPUS construct that evaluated participants on their usability satisfaction with the intention to know how satisfied they are with the web portal system and its usefulness in executing tasks. Clearly, participants were highly dissatisfied on their overall satisfaction on the ease to use UNIBEN Web Portal for executing academic related activities, but were merely satisfied with the general web portal system.

Table 4: UNIBEN Web Portal Usefulness Profile.

\begin{tabular}{|l|c|c|c|c|c|}
\cline { 2 - 5 } \multicolumn{2}{|c|}{ Preferences } & \multicolumn{3}{c|}{ Usability Evaluation on Web Portal Usefulness } \\
\cline { 2 - 6 } & $\begin{array}{c}\text { Strongly } \\
\text { Agree }\end{array}$ & Agree & Neutral & Disagree & $\begin{array}{c}\text { Strongly } \\
\text { Disagree }\end{array}$ \\
\hline It was simple to use the Portal system. & $20(05.1 \%)$ & $221(56.1 \%)$ & $41(10.4 \%)$ & $128(32.5 \%)$ & $04(01.0 \%)$ \\
\hline $\begin{array}{l}\text { I could effectively complete my academic } \\
\text { related tasks and scenarios using the } \\
\text { portal system. }\end{array}$ & $36(09.1 \%)$ & $102(25.9 \%)$ & $29(07.4 \%)$ & $189(48.0 \%)$ & $38(09.6 \%)$ \\
\hline $\begin{array}{l}\text { Whenever I made a mistake using the } \\
\text { system, I could recover easily and quickly. }\end{array}$ & $38(09.6 \%)$ & $62(15.7 \%)$ & $76(19.3 \%)$ & $168(42.6 \%)$ & $50(12.7 \%)$ \\
\hline $\begin{array}{l}\text { I was able to quickly complete my } \\
\text { academic tasks and scenarios using the } \\
\text { portal system. }\end{array}$ & $40(10.2 \%)$ & $92(23.4 \%)$ & $68(17.3 \%)$ & $176(44.7 \%)$ & $18(04.6 \%)$ \\
\hline $\begin{array}{l}\text { I was able to efficiently complete the tasks } \\
\text { and scenarios using the portal system on } \\
\text { my own. }\end{array}$ & $15(03.8 \%)$ & $32(08.1 \%)$ & $78(19.8 \%)$ & $207(52.5 \%)$ & $62(15.7 \%)$ \\
\hline I felt comfortable using the portal system. & $22(05.6 \%)$ & $121(30.7 \%)$ & $17(04.3 \%)$ & $196(49.7 \%)$ & $38(09.6 \%)$ \\
\hline $\begin{array}{l}\text { It was easy to learn to use the portal } \\
\text { system. }\end{array}$ & $27(06.9 \%)$ & $79(20.1 \%)$ & $179(45.4 \%)$ & $86(21.8 \%)$ & $23(05.8 \%)$ \\
\hline $\begin{array}{l}\text { I believe using the portal system has } \\
\text { improved my learning experience. }\end{array}$ & $08(02.0 \%)$ & $66(16.6 \%)$ & $232(58.9 \%)$ & $72(18.3 \%)$ & $16(04.1 \%)$ \\
\hline
\end{tabular}

Table 5: UNIBEN Web Portal Satisfaction Profile.

\begin{tabular}{|l|c|c|c|c|c|}
\cline { 2 - 6 } \multicolumn{2}{c|}{ Preferences } & \multicolumn{4}{c|}{ Participant's Overall Satisfaction } \\
\cline { 2 - 6 } $\begin{array}{l}\text { UNIBEN Web Portal } \\
\text { Usability Satisfaction }\end{array}$ & $\begin{array}{c}\text { Highly } \\
\text { Satisfied }\end{array}$ & Satisfied & Neutral & Dissatisfied & $\begin{array}{c}\text { Highly } \\
\text { Dissatisfied }\end{array}$ \\
\hline $\begin{array}{l}\text { Overall usability satisfaction on how easy it } \\
\text { was to use UNIBEN Web Portal for } \\
\text { academic purposes is? }\end{array}$ & $38(09.6 \%)$ & $67(17.0 \%)$ & $40(10.2 \%)$ & $123(31.2 \%)$ & $126(32.0 \%)$ \\
\hline $\begin{array}{l}\text { Overall satisfaction with UNIBEN Web } \\
\text { Portal System is? }\end{array}$ & $58(14.7 \%)$ & $99(25.1 \%)$ & $87(22.1 \%)$ & $96(24.4 \%)$ & $54(13.7 \%)$ \\
\hline
\end{tabular}




\section{DISCUSSIONS}

It was the scope of this study to look at the usability or "ease of use" of University of Benin (UNIBEN) web portal (uniben.waeup.org) from the view of students who are users of this technology and thus, to know what usability meant to students with regards to the systems usefulness.

The study employed the survey approach using constructs from the developed WEBPUS Model as results revealed that majority of the students were ICT competent with basic computer/internet related tasks which should have increased the usefulness of the UINBEN web portal system, but there was an implication that the portal usability has neither encouraged their internet usage nor the ability to interact and socialize (socio-academic activities) with the portal system because the amount of time spent on the portal on a weekly basis by majority of the students was pitifully less than an hour.

It also unveiled that the informative content of the UNIBEN web portal system was ineffective implying that students could not ascertain to the fact that it was helpful in completing their tasks or has helped improved their learning experiences majorly because if an error was made, it was difficult to recover as many highly disagreed on the error messages intended to fix the mistake made, but rather they would avoid using the system themselves in order not to make such mistake. A critical implication from the findings of this study is the fact that the students cannot efficiently complete their task without user support while using the web portal system: this is the more reason they go to CRPU at the Main Auditorium or most preferably cyber cafes (who may unequally extort students for such services) for academic activities regarding portal usage.

\section{CONCLUSION}

It is no doubt Obafemi Awolowo University (OAU) Ileife was rated best in 2013's webometric ranking. Although the university web portal is still in its development process, the fact that the web portal usability goal (the ease to use) has not been materialized from the student's perspective is not an impact that can be much endured with Nigeria's twice best university in webometric (2012). It is a pitiful reality as students run to cyber cafes whenever they want to use the portal system regarding academic activities online. To this end, it is reasonable to conclude here that the usefulness of the university web portal is merely effective or efficient to the students in completing tasks online irrespective of their competence level in Information and Communication Technology (ICT). Contributory to wealth of information, this study has exposed us to the concept of and also helped in understanding web portal usability and provided guidelines or framework for improving on features that will drive usability factor in web portal application development (for developers such as WAeUP) for Nigerian universities (owners and others yet to adopt such technology).

\subsection{Recommendation}

Social network portal application with less or no user support attracts users from different walks of life to use such portals because of certain features and functionalities that may be needed in educational web portals to increase its usefulness and improve user's learning experiences. With indications from this study, it is recommended that Nigerian universities with web portals (specifically UNIBEN ICT Centre) ought to provide students (users) with a given specified training and user support, with the goal of increasing the ease of use and learnability to effectively and efficiently fulfill a specified range of task scenarios on the web portal while managements achieve their economic and global attainments. Also, developers are to refine the educational web portal systems into a social-academic system to reduce traffic from social network portals to academic web portals.

\section{ACKNOWLEDGMENT}

Immense gratitude goes to Information Technology and Mobile Research Lab (ITML) and group members who invested their enormous time through the field activities to the final analysis. Thanks also to the project team whose memory of information and creativity is never empty.

\section{REFERENCES}

[1] Oliha F. O. and Ekuobase, G. O. "A look on the usability factor of University Web Portal: User's perspective", UNIBEN Journal of Science, (in press)

[2] Olasina G. "Students' Perceptions of E-Registration at Ladoke Akintola University of Technology, Ogbomoso, Nigeria", http://unilorin.edu.ng Lpublications/olasinage. Accessed May 2011. 
[3] Ballard J. K. "Web Site Usability: A Case Study of Student Perceptions of Educational Web Sites", http://www.tobii.com. Accessed on May 2010.

[4] Tolentino M. N. (2011), "University Web Portals As Information Management Tool: Technology Acceptance Dimension", International Journal of Management \& Information Systems. Vol.15, Number 3, 2011, pp 221-225.

[5] CampusPortal. "Ranking Web of Universities (Webometrics): Top 100 best Universities in Nigeria - 2013" campusportal.com.ng/education/top-100best-university-in-nigeria-2013-universityranking/1700/ Accessed on September 2013.

[6] Mentes S. A. and Turan A H. "Assessing the Usability of University Websites: An Empirical Study on Namik Kemal University", TOJET: The Turkish Online Journal of Educational Technology, Vol 11, Number 3, 2012, pp 61-69.

[7] Sindhuja, P.N. and Surajith, G.D. "Impact of the factors influencing website usability on user satisfaction",
The IUP Journal of Management Research, Vol. 8, Number 12, 2009, pp54-66.

[8] Preece, J., Rogers, Y., Sharp, H., Benyon, D., Holland, S., \& Carey, T. Human-Computer interaction. AddisonWesley, Wokingham, England: 1994.

[9] Levi M. D. and Conrad F. G. "Usability Testing of World Wide Web Sites". http://www.bls.gov/ore/ htm papers/st9601050.htm. Accessed on January 2, 2001.

[10] Chiew T. K. and Salim S. S. "Webuse: Website Usability Evaluation Tool", Malaysian Journal of Computer Science, Vol. 16 Number 1, 2003, pp. 4757.

[11] Lewis J. R. "IBM Computer Usability Satisfaction Questionnaires: Psychometric Evaluation and Instructions for Use", International Journal of Human Computer Interaction, Vol. 7, Number 1, 1993, pp 141. 